\title{
LAS FORTALEZAS DE LA ISLA DE LA PALMA DURANTE LA SEGUNDA MITAD DEL SIGLO XVI
}

\author{
THE FORTRESSES OF THE ISLAND OF LA PALMA DURING THE \\ SECOND HALF OF THE 16TH CENTURY
}

\author{
Manuel Lobo Cabrera* y Sergio Hernández Suárez**
}

Fecha de recepción: 9 de enero de 2019

Fecha de aceptación: 22 de julio de 2019

Cómo citar este artículo/Citation: Manuel Lobo Cabrera y Sergio Hernández Suárez (2019). Las fortalezas de la isla de La Palma durante la segunda mitad del siglo XVI. Anuario de Estudios Atlánticos, $\mathrm{n}^{\mathrm{o}}$ 66: 066-015. http://anuariosatlanticos.casadecolon.com/index.php/aea/article/view/10548/9917 ISSN 2386-5571. https://doi.org/10.36980/10548.9917

Resumen: La construcción de las tres principales fortalezas de la isla de La Palma durante el siglo XVI (fortaleza de Santa Catalina, torre de San Miguel y fuerte del Cabo), se consolidó como un medio para defender la isla de los ataques corsarios surgidos a raíz de los conflictos bélicos entre la Monarquía Hispánica y el resto de potencias europeas, evidenciando una clara evolución defensiva entre el ataque del corsario francés François Le Clerc (1553) y el perpetrado por el corsario inglés Francis Drake (1585).

Palabras clave: fortalezas, La Palma, siglo XVI, Monarquía hispánica, François Le Clerc, Francis Drake.

\begin{abstract}
The construction of the three main fortresses of La Palma island during the 16th century (Santa Catalina Fortress, San Miguel Tower and the Fort of the Cabo) was established as an instrument to defend the island against the corsairs attacks that appeared due to the warlike conflicts between the Spanish Monarchy and the rest of the European powers, showing an evident evolution of the defensive structures between the attack of the French corsair François Le Clerc (1553) and the one perpetrated by the English corsair Francis Drake (1585).
\end{abstract}

Keywords: Fortress, La Palma, XVI century, Spanish Monarchy, François Le Clerc, Francis Drake.

\section{INTRODUCCIÓN}

Las islas Canarias constituyeron, desde el mismo momento de su conquista, un emplazamiento en el cual la Corona de Castilla se apoyó para desarrollar de una manera más eficiente sus relaciones comerciales con las nuevas tierras descubiertas al otro lado del Atlántico. Todo ello generó un floreciente tráfico comercial en el archipiélago, especialmente en las islas de realengo, entre las que destacamos a La Palma, y su capital, Santa Cruz, como la última y más importante de las escalas que los navíos realizaban en las travesías hacia las Indias. Así, esta ciudad es considerada por la mayoría de los historiadores como la poseedora del puerto más importante de cuantos existían en el archipiélago durante el siglo XVI, basando

1 Trabajo cofinanciado por la Agencia Canaria de Investigación, Innovación y Sociedad de la Información de la Consejería de Economía, Industria, Comercio y Conocimiento y por el Fondo Social Europeo (FSE) Programa Operativo Integrado de Canarias 2014-2020, Eje 3 Tema Prioritario 74 (85\%).

* Catedrático de Historia Moderna de la Universidad de Las Palmas de Gran Canaria. C/ Rembrandt, $\mathrm{n}^{\circ}$ 4. 35017. Las Palmas de Gran Canaria. España. Teléfono: +34 928 451 714; correo electrónico: manuel.lobo@ulpgc.es.

** Investigador del Departamento de Ciencias Históricas de la Universidad de Las Palmas de Gran Canaria. C/ Pérez del Toro, $n^{\circ} 1,35004$. Las Palmas de Gran Canaria. España. Teléfono: +34 928458 922; correo electrónico: sergio.hernandez@ulpgc.es. Orcid id: orcid.org/0000-0002-3482-9971 
su riqueza en el trasiego del tráfico comercial marítimo entre las nuevas tierras americanas y la península ibérica, y en el comercio de exportación de productos como el azúcar, y sobre todo el vino, hacia los territorios europeos ${ }^{2}$.

Sin embargo, las consecuencias negativas de este incipiente comercio marítimo no tardaron en llegar, y las expediciones extranjeras comenzaron a merodear por las costas canarias, generalmente con la intención de saquear y robar en aquellos puertos tan desprovistos de defensa por parte de la Corona española.

De esta manera, y debido a la desprotección que sufría la ciudad de Santa Cruz de La Palma, tanto la Corona como el Cabildo se vieron obligados durante todo el siglo XVI, pero de manera más eficaz durante su segunda mitad, a tomar medidas para la fortificación de la zona más proclive a la entrada de enemigos extranjeros, la cual se situaba precisamente en la costa de la capital insular, y así proteger uno de los puertos comerciales fundamentales en la carrera colonial de la Monarquía hispánica. En efecto, dotar a La Palma de una defensa militar efectiva constituyó, en muchos momentos del siglo, un gran problema derivado de la falta de recursos económicos que durante la mayor parte de la centuria padeció el Cabildo insular ${ }^{3}$, aunque, como iremos explicando, se intentó paliar con medidas frecuentes como los repartimientos entre los vecinos $^{4}$ o la ayuda indirecta de la Corona, mediante el envío de ingenieros militares, como Leonardo Torriani o Próspero Casola, que procuraron solventar de primera mano aquellas deficiencias defensivas planteadas en islas como La Palma.

\section{CONTEXTO POLÍTICO: LOS CONFLICTOS BÉLICOS DE LA CORONA ESPAÑOLA, REFLEJADOS EN LOS PRINCIPALES ATAQUES CORSARIOS A LA PALMA}

A lo largo de todo el siglo XVI, la mayoría de los ataques corsarios a Canarias tuvieron explícitos motivos políticos, que coincidieron expresamente con las disputas bélicas en las que se hallaba la Monarquía hispánica. Así, como señala Rumeu ${ }^{5}$, los primeros piratas que arribaron a las islas tras su conquista fueron portugueses, en clara conexión con las contiendas atlánticas entre las dos principales coronas ibéricas. Posteriormente, y a lo largo de todo el siglo XVI, los ataques corsarios fueron numerosos y continuos, aunque a grandes rasgos podemos afirmar que, conforme avanza la centuria, la presencia lusitana pierde fuerza en favor de los dos grandes rivales de los dos Austrias mayores, tanto dentro de Europa como en el océano Atlántico: Francia e Inglaterra.

\section{François Le Clerc, "Pie de Palo” (1553)}

Con respecto a Francia, prácticamente desde el inicio del reinado de Carlos V, las disputas con Francisco I son continuas. Todo ello afecta de manera directa al archipiélago, por medio de la presencia de navíos franceses en La Palma con la intención de saquear la ciudad de Santa Cruz de La Palma ${ }^{6}$. Durante la primera mitad del siglo, la intentona más considerable la produce el corsario francés Bnabo (1537), que, aunque halla una isla desprotegida en cuanto a sus fortalezas, sufre el revés de encontrarse con algunos galeones castellanos, que en su regreso desde América defienden la isla, con lo que su ataque resulta infructuoso ${ }^{7}$.

Sin embargo, el siguiente ataque francés a La Palma cambiará para siempre el devenir de la isla en la cuestión defensiva: nos referimos al perpetrado por François Le Clerc, más conocido como "Pie de Palo" e iniciado el 21 de julio de 1553, a su regreso de las Antillas (que también saquearon) y tras haber fracasado en su intento de asaltar Gran Canaria y Tenerife. Según el cronista azoreano Gaspar Frutuoso:

2 SANTANA PÉREZ (2014), p. 78.

3 CASTELLANO GIL (1991), p. 11.

4 CASTELLANO GIL (1991), p. 19.

5 RUMEU DE ARMAS (1991), Tomo I, p. 14

6 SANTANA PÉREZ (2014), p. 84.

7 CASTELLANO GIL (1991), p. 45. 
Y en llegando al puerto comenzaron a disparar sus tiros con tanta furia sobre las compañías y la ciudad, que nadie osó aguardarlos; y mientras la artillería jugaba, encubiertos con la humareda y otros artificios que de industria hacían, saltaron en tierra sin que nadie se les opusiese pues todos huían sin aguardar marido por mujer ni padre por hijo y así toda la $\operatorname{ciudad}^{8}$.

En este momento, la ciudad de Santa Cruz de La Palma cuenta únicamente con la torre de San Miguel, la cual no evita en absoluto la entrada de los corsarios franceses a la ciudad por el barrio del Cabo. Parece evidente que desde algunos años antes los propios integrantes del Cabildo eran conscientes de tal carestía defensiva, cuando en sesión capitular de 1 de diciembre de 1550 se solicita al rey el envío de artillerías para la única fortaleza de la isla, o en su defecto, una merced para que el Cabildo cobrara directamente las penas de cámara en las siguientes dos décadas, y de esta forma se pudiera financiar la compra de artillería 9 .

Durante el ataque de Le Clerc, desembarcaron en la capital palmera «500 infantes - 300 arcabuceros y 200 piqueros ${ }^{10}$, lo que provocó que la mayoría de la población capitalina huyera hacia el interior y dejara la ciudad completamente a merced de los hugonotes franceses. Según Rumeu, las tropas extranjeras se hacen con el territorio en apenas media hora, sin que Le Clerc llegara a pisar tierra durante todo el tiempo que sus tropas ocuparon la ciudad. Además, algunas de las familias más distinguidas de la nobleza palmera fueron capturadas como, por ejemplo, la mujer e hijos del regidor Pedro Sánchez de Estupiñán ${ }^{11}$. El gobierno de la isla, constituido por la Justicia y el regimiento, decide huir en su gran mayoría hacia Tazacorte, donde establece provisionalmente el Cabildo, y solicita la ayuda inmediata del gobernador Miranda, máxima autoridad del Cabildo de Tenerife y de la propia isla de La Palma ${ }^{12}$.

En su estancia en la ciudad, alargada hasta el día 30 de julio ${ }^{13}$, las tropas de Le Clerc cometen pillaje de una manera minuciosa, exigiendo a las autoridades palmeras una cantidad de 30.000 ducados para su liberación. Al no contar con tan amplia suma, el licenciado Arguijo (teniente de gobernador y máxima autoridad palmera) opta por no responder a las exigencias francesas, y el abandono de la ciudad por parte de Le Clerc y sus tropas se debe únicamente al agotamiento de alicientes en sus expectativas de saqueo ${ }^{14}$.

Se trata, sin lugar a dudas, de uno de los ataques más briosos que sufrió la ciudad de Santa Cruz de La Palma en toda su historia, si tenemos en cuenta el enorme daño que se provocó directamente a la urbe, refiriéndonos tanto a las edificaciones y lugares públicos como a la documentación existente, la cual, desgraciadamente, fue pasto de las llamas, por lo que se eliminó cualquier acta cabildicia en fecha anterior al 21 de julio de 1553. Sin embargo, este asalto marcó enormemente la política posterior de defensas del Cabildo, reforzándolas de tal manera que se consiguió repeler, como observaremos más adelante, al mismísimo corsario británico Francis Drake.

Sea como fuere, lo cierto es que, tras la desoladora situación de la ciudad tras el ataque francés, el capitán de Gran Canaria por entonces, Pedro Cerón, consideró que la defensa debió haber sido más brava, con lo que la responsabilidad recaía directamente en la Justicia, cargo ocupado por el licenciado Arguijo, y por los regidores del Cabildo, aspecto que no dudó en comunicar al rey, exigiéndole medidas al respecto, por lo que el monarca instó a hacer las averiguaciones correspondientes al nuevo gobernador de Tenerife y La Palma, Juan López de Cepeda. En este caso, la máxima autoridad insular no consideró oportuno aplicar cualquier medida punitiva a cualquiera de los integrantes del Cabildo, a pesar de las evidencias mostradas al respecto de su culpabilidad ${ }^{15}$.

Lo que sí parece evidente es el profundo temor que despertó el ataque de 1553 tanto a la población como a la corporación insular. Ello se refleja continuamente en las actas del Cabildo,

8 FRUTUOSO (1964), p. 112.

9 MARTÍN RODRÍGUEZ (1995), p. 198.

10 RUMEU DE ARMAS (1991), Tomo I, p. 151.

11 RUMEU DE ARMAS (1991), Tomo I, p. 153.

12 CASTELLANO GIL (1991), p. 47.

13 PINTO DE LA ROSA (1996), p. 338.

14 RUMEU DE ARMAS (1991), Tomo I, p. 153.

15 RUMEU DE ARMAS (1991), Tomo I, p. 156. 
cuando, ante cualquier noticia de un posible ataque de mano de los franceses, se solicita a los guardas que velen día y noche en las fortalezas, para que, llegado el momento del avistamiento, las milicias palmeras contaran con el tiempo suficiente para organizarse en torno a las torres de las fortalezas ${ }^{16}$.

Algunos lustros después, y más concretamente en 1570, Jacques de Sores, que en el ataque de 1553 a Santa Cruz de La Palma había sido el lugarteniente en tierra de François Le Clerc, retorna a aguas canarias, en este caso en persecución del navío Santiago, el cual había zarpado desde Lisboa con 69 misioneros, liderados por Ignacio de Azevedo. Tras una considerable parada en Madeira, a la que Sores arriba para asaltarlo, el galeón Santiago continuó su viaje hacia el puerto de Santa Cruz de La Palma, y en un contratiempo, a todas luces climatológico, Azevedo y sus hombres, a bordo del galeón, se ven obligados a refugiarse en el puerto de Tazacorte. Tras unos días, prosiguen su travesía hacia el puerto de Santa Cruz, pero a la altura de Fuencaliente, Sores arriba la embarcación y, ayudado por los navíos franceses que le secundaban, termina por tomar el barco y asesinar a la mayoría de sus tripulantes, entre ellos al mismo Ignacio de Azevedo, en lo que la historiografía ha denominado como los Mártires de Tazacorte ${ }^{17}$.

\section{Francis Drake (1585)}

Por otro lado, y fruto de las bélicas relaciones entre Felipe II y la Corona inglesa, especialmente desde el ascenso al trono de Isabel I, La Palma también se vio afectada por los corsarios británicos, aunque en un espacio temporal más cercano al final del siglo XVI ${ }^{18}$. Hablamos, obviamente, del ataque perpetrado por el famoso corsario inglés Francis Drake en noviembre de 1585 a la capital palmera, uno de los episodios más estudiados dentro de la historiografía de La Palma ${ }^{19}$.

Recordando los nefastos episodios ocurridos en el año 1553, desde aquel momento, los empeños tanto del Cabildo de la isla como de la Corona se centraron en crear una defensa militar más eficiente. Esta situación se deduce del informe realizado por parte del Cabildo el 13 de agosto de $1554 \mathrm{y}$ en el cual se encontraba presente directamente el gobernador Cepeda, quien es informado de la necesidad de una mayor eficacia en las fortificaciones, a la vez de la insuficiencia de la artillería, por lo que se harían necesarias, a juicio del propio informe, «seis piezas gruesas de bronce», con las que las fortalezas quedarían bien suministradas ${ }^{20}$.

Para ello, se procede a la reparación de la torre de San Miguel, devastada en el mencionado ataque de 1553 y que, según Rumeu, para el año 1554 ya se encontraba prácticamente reparada y terminada, a falta de las piezas de artillería que posteriormente fueron arribando a la isla ${ }^{21}$. Seguidamente, se construye el castillo de Santa Catalina, considerado como el principal de la isla y cuyas obras se iniciaron antes del ataque de François Le Clerc ${ }^{22}$ y culminaron a finales de septiembre de $1560^{23}$ a costa de Juan de Monteverde, quien, a cambio de su título de capitán general de La Palma y alcaide de las fortalezas, se había comprometido a reparar la torre de San Miguel, aunque finalmente el gobernador Juan López de Cepeda dedicara los repartimientos demandados a los vecinos a esta torre (valorados en unos 3000 ducados), y encomendara al

16 Archivo Municipal de Santa Cruz de La Palma (en adelante, lo abreviaremos como AMSCLP), Libro de Acuerdos del Cabildo 1559-1567, Acta del día 13 de enero de 1559.

17 PINTO DE LA ROSA (1996), p. 341.

18 LOBO CABRERA (2018), p. 77.

19 POGGIO, REGUEIRA y HERNÁNDEZ (2014), p. 210.

20 RUMEU DE ARMAS (1991), Tomo II, Primera Parte, p. 240

21 RUMEU DE ARMAS (1991), Tomo II, Primera Parte, p. 237.

22 Aunque Rumeu afirma que la construcción del castillo de Santa Catalina ya estaba desarrollado antes de 1553, también afirma que no estaba preparada para abrir fuego en contra de la invasión francesa (RUMEU DE ARMAS (1991), Tomo II, Primera Parte, p. 235).

23 Aunque hemos consultado directamente el acta del Cabildo de La Palma en cuestión, debido al deterioro del legajo descrito, no es posible conocer la fecha exacta, aunque con certeza afirmamos que se trata del 28 o 29 de septiembre de 1560 , debido a que el acta anterior data del día 27 de septiembre y el acta posterior corresponde al día 30 de septiembre de 1560 (Libro de Acuerdos del Cabildo 1559-1567). 
propio Juan de Monteverde que sufragara la finalización del castillo de Santa Catalina ${ }^{24}$. Finalmente fue construida la torre de Santa Cruz del barrio del Cabo en 1578, la menor de los tres fuertes principales que completan una amplia defensa frente a los posibles ataques futuros ${ }^{25}$, aunque en un informe realizado en 1591 aparezca como derruida «por una avenida del barranco» $^{26}$.

En efecto, tras el ascenso al trono británico de Isabel I, el conflicto entre las coronas de España e Inglaterra se intensificó, lo que hacía más que previsible un ataque durante el último cuarto del siglo XVI al puerto de Santa Cruz de La Palma, famoso ya en toda Europa por ser una fructífera escala que los navíos acostumbraban a utilizar en su largo camino hacia las Indias $^{27}$. La hipotética ofensiva finalmente tuvo lugar en noviembre de 1585: desde finales de septiembre, el gobernador de Tenerife había sido informado sobre la partida desde los puertos ingleses de una serie de navíos hacia el Atlántico, liderados por el corsario Francis Drake, con lo que existían posibilidades certeras de un intento de ataque a alguno de los puertos españoles. La información se recrudeció cuando el 25 de octubre, el marqués de Lanzarote avisó al gobernador tinerfeño del avistamiento de barcos extranjeros en la isla de Lobos ${ }^{28}$. Rápidamente, el citado gobernador mandó esta carta a la justicia y el regimiento de La Palma, que recibió en acta de 4 de noviembre de 1585. En vista de que el ataque era más que probable, el Cabildo de La Palma se reúne, acordando una serie de medidas al respecto, como pasar revista a todas las fortalezas, más las artillerías disponibles, a la vez que montar guardias continuas de vigilancia a la $\operatorname{costa}^{29}$. De esta manera, y cumpliendo con las previsiones del gobierno insular, Drake se encontraba frente a las costas de la ciudad el día 7 de noviembre, situación que produce una lógica alarma entre la población palmera, por lo que todas las milicias de la isla se agrupan en torno a las fortalezas capitalinas. En este caso, los contingentes reunidos agrupaban un total de 2045 soldados, de los cuales 600 eran arcabuceros y 1445, piqueros. La alerta en la isla se mantuvo durante cinco días, tras lo cual, el 12 de noviembre, la mayoría de las fuerzas retornaron a las diferentes poblaciones del territorio insular ${ }^{30}$.

A pesar de que durante casi una semana desaparece, previsiblemente en aras de una empresa mayor como era la de asaltar una ciudad más rica como Las Palmas (y en la que finalmente desiste), Drake retorna al litoral palmero y comienza a perpetrar su ataque el día 13 del mismo mes.

Para este momento, según Pinto:

el Fuerte de San Miguel [estaba] artillado con 4 cañones, siendo su Alcaide Bartolomé González Acosta; el Castillo de Santa Catalina, con 10 piezas de artillería, cuyo alcaide era Pedro Hernández Señorino; y el Fuerte del Cabo, defendido por dos pequeños cañones ${ }^{31}$.

A pesar de su intento de desembarcar por la playa de Bajamar, lo cierto es que los cañones de San Miguel acertaron en sus disparos al navío Bonaventure, en el que viajaba Francis Drake y en el cual comandaba toda la operación. Seguidamente, los demás capitanes se congregaron para socorrerlo de tal manera que desde la misma torre de San Miguel se acertó a dañar a numerosos barcos. A pesar de que Drake ordenara, en un último intento, el desembarco por Bajamar, desde la citada torre se repelieron las barcazas mediante disparos de artillería, con lo que unas siete horas después del inicio del ataque ${ }^{32}$, Drake decide abandonar el litoral palmero, de manera que las milicias insulares consiguen repeler a uno de los más destacados corsarios de Isabel I por sus propios medios ${ }^{33}$.

24 RUMEU DE ARMAS (1991), Tomo II, p. 239.

25 CASTELLANO GIL (1991), p. 5.

26 RUMEU DE ARMAS (1991), Tomo II, Primera Parte, p. 248.

27 POGGIO CAPOTE (2014), p. 14.

28 RUMEU DE ARMAS (1991), Tomo II, Primera Parte, p. 13.

29 AMSCLP, Libro de Acuerdos del Cabildo 1571-1586, Acta del día 4 de noviembre de 1585.

30 ORTIGUEIRA, POGGIO, HERNÁNDEZ y HERNÁNDEZ (2014), p. 161.

31 PINTO DE LA ROSA (1996), p. 343.

32 POGGIO y otros (2014), p. 215.

33 LOBO CABRERA (2018), p. 82 
En definitiva, la derrota de Drake, a todas luces inesperada, merced a la facilidad con la que había accedido a algunos puertos del noroeste peninsular como $\mathrm{Vigo}^{34}$, se consiguió como consecuencia de las actuaciones que desde el ataque de Le Clerc se fueron realizando en la construcción y consolidación de las fortalezas defensivas de la isla, de manera que en algunos informes de finales de siglo dirigidos a la Corona se explicite que la isla cuenta con «una fortaleza y otros dos fuertes» ${ }^{35}$. Además, a los trabajos arquitectónicos se unió, por un lado, la rápida reacción de las milicias palmeras, y sobre todo, la dirección de la defensa por parte de los dirigentes insulares, factor que difiere notoriamente de lo acaecido en 1553, cuando la Justicia y el regimiento huyen de la ciudad sin plantar cara al corsario francés, ante la evidencia de una derrota más que probable.

\section{ACCIÓN DE LOS INGENIEROS MILITARES A LO LARGO DEL SIGLO XVI}

Los primeros intentos de construcciones militares defensivas en La Palma se concretan en una fecha anterior al año 1515 , cuando a priori ya se encuentra terminada la torre de San Miguel. Según Rumeu, sería la primera construcción militar defensiva de todas las islas ${ }^{36}$. Durante la década de los años 20, el emperador Carlos V concede dos cédulas reales a la isla: la primera de ellas, datada el 15 de marzo de 1528, autorizaba al Cabildo para realizar repartimientos entre los vecinos con el fin de fortificar la ciudad de Santa Cruz; la otra, de 8 octubre de 1539, concedía al gobierno insular el cobro de una sisa del vino hasta una cantidad de 400 ducados, los cuales permitirían obtener fondos para la compra de artillería y la construcción de nuevos fuertes, de cara a robustecer las defensas de la isla ${ }^{37}$.

Sin embargo, las acciones más decididas de la Corona para solventar los problemas defensivos de Santa Cruz de La Palma se produjeron durante el reinado de Felipe II, pues desde la construcción de la torre de San Miguel a comienzos de siglo, las fortificaciones palmeras apenas habían sufrido algunas variaciones de escasa importancia ${ }^{38}$. Así, durante la segunda mitad del siglo es cuando Felipe II comienza a convocar a corte a los mayores expertos en cuanto a fortificaciones defensivas. Dado que las innovaciones más desarrolladas en cuanto a ingeniería militar se encontraban enmarcadas dentro del Renacimiento italiano, contando, por ejemplo, con el nuevo «sistema abaluartado» ${ }^{39}$, Felipe II hace llamar a un ingeniero militar cremonés de enorme relevancia llamado Leonardo Torriani, que ya había prestado sus servicios al emperador del Sacro Imperio Germánico Rodolfo II de Habsburgo e incluso había trabajado a las órdenes de Felipe II en la construcción de las fortalezas defensivas portuguesas ${ }^{40}$.

\section{LA ACTIVIDAD DE LEONARDO TORRIANI}

Así, el monarca le encomienda, mediante la Real Cédula de 18 de marzo de 1584, la planificación de las fortificaciones de las islas Canarias al ingeniero italiano Leonardo Torriani $^{41}$, el cual viaja inicialmente a La Palma, a la que arriba en 1584, previa petición del regidor Benito Cortes de Estupiñán, quien incluso llega a trabajar y a recibir las instrucciones directas del propio Torriani en los momentos en los que este se ausentó de la isla ${ }^{42}$. Torriani tenía muy claro que, aunque el plan monárquico era la defensa total de las islas, el objetivo principal era la fortificación de aquellas ciudades costeras que mayor peligro pudiesen correr, ya

34 ORTIGUEIRA y otros (2014), p. 167.

35 MARCO DORTA (1943), p. 203.

36 MARTÍN RODRÍGUEZ (1995), p. 197.

37 RUMEU DE ARMAS (1991), Tomo II, Primera Parte, p. 235.

38 CASTELLANO GIL (1991), p. 22.

39 FERNÁNDEZ (2001), p. 57.

40 MARTÍN RODRÍGUEZ (1986), p. 22.

41 TORRIANI (1959), Introducción, p. 17.

42 MARTÍN RODRÍGUEZ (1986), p. 24. 
que eran las más ansiadas para un posible ataque y saqueo rápido por parte de los piratas y corsarios extranjeros ${ }^{43}$.

Asimismo, Felipe II solicita a Torriani que las defensas militares no deben ir encauzadas hacia los ataques de los ejércitos regulares extranjeros, pues consideraba que la soberanía de las islas no corría peligro, sino de los piratas y corsarios que recalaban de manera esporádica en las islas para asaltarlas y saquearlas, sin mayor interés que el económico, y que en una contienda larga no disponían de poder ofensivo para resistir a una defensa prolongada de la ciudad ${ }^{44}$. En este caso, Torriani parecía estar de acuerdo con el monarca, pues en su obra Descripción de las islas Canarias afirma que:

Siendo estas islas molestadas por los corsarios que saquean a través de este gran mar Océano, y cuyo fin es el robar sin pelea o ponerse en riesgo de consideración, la fortificación que se pretende hacer en estas islas no debe ser real, puesto que aquí no se hallan montes de oro ni de plata, que sirvan de cebo para que la gente poderosa organice grandes empresas, de modo que se puedan esperar gran ejército, larga estancia y fuerte batería ${ }^{45}$.

A la referida afirmación, el ingeniero cremonés añadía que, aunque se aspirase a construir una gran fortificación, esta debería ser custodiada por un gran número de hombres, que, en su opinión, superarían incluso a la población de la isla, por lo que a todas luces lo consideró inviable ${ }^{46}$.

Empero, a las instrucciones defensivas dadas a Torriani, se le añadía la misión de construir el muelle de Santa Cruz de La Palma, pues Felipe II era consciente de que, tras los puertos de Amberes y Sevilla, se constituía como el tercer puerto comercial de mayor importancia en todos sus territorios europeos ${ }^{47}$. Su construcción se inició en 1584 como medida para sustituir el antiguo embarcadero de la ciudad, el cual había agrupado todo el tráfico naval de la isla durante la mayoría del siglo XVI. De esta manera, el nuevo puerto de Santa Cruz de La Palma, proyectado en torno a la torre de San $\mathrm{Miguel}^{48}$, se consideraría a todos los efectos el primero construido en el archipiélago ${ }^{49}$.

A pesar de las enormes intenciones de Torriani en Santa Cruz de La Palma, lo cierto es que en 1586 regresa de nuevo a la Corte prácticamente sin ninguna obra finalizada, aunque con el puerto iniciado, y con instrucciones precisas al mencionado Benito Cortés de Estupiñán para que se continuaran las obras ${ }^{50}$. Lo más notable de Torriani durante su primera estancia en la isla fue que, aparte de realizar los planos para las posteriores remodelaciones de las defensas capitalinas, fue testigo directo del mencionado ataque del corsario inglés Francis Drake en noviembre de $1585^{51}$, el cual describe en su obra Descripción de las islas Canarias de la siguiente manera:

Año 1585, a 13 de noviembre, Francisco Drake inglés, siendo enviado por la reina de Inglaterra con treinta navíos y 4000 peones, [...] hasta que llegó a la ciudad de esta isla. Al querer desembarcar, se le contestó con tan buen orden por la artillería de los tres castillos que están en la playa de la ciudad, que fue obligado a salir del puerto con pérdidas; y también había allí, en la marina, 2000 hombres bien armados, que, apoyándose en la aspereza de la tierra, de las olas del mar y de las fortalezas, estaban prontos para defender valerosamente su patria ${ }^{52}$.

Tras aproximadamente un año fuera de las islas, Felipe II le envía de nuevo al archipiélago, con Cédula Real con fecha de 20 de mayo de 1587, donde se refleja que:

43 FERNÁNDEZ (2001), p. 64.

44 FERNÁNDEZ (2001), p. 59.

45 TORRIANI (1959), p. 53.

46 TORRIANI (1959), p. 54.

47 FERNÁNDEZ (2001), p. 59.

48 PINTO DE LA ROSA (1996), p. 361.

49 FERNÁNDEZ (2001), p. 59.

50 TORRIANI (1959), Introducción, p. 18.

51 MARTÍN RODRÍGUEZ (1986), p. 24.

52 TORRIANI (1959), p. 228. 
Por quanto por los avisos que se tienen, se sabe que en las mares del poniente andan navíos de enemigos corsarios, de quien se puede presumir yntentarán de emprender de saquear las yslas de Canaria o alguna dellas, y a mi servicio y bien de mis súbditos que viven en ellas conviene se fortifiquen las partes más importantes y ponerlas en defensa; y para prevenir y proveer en lo más acertadamente e nombrado a Leonardo Turriano y mandádole que como ingeniero vaya a ver y visitar [las islas Canarias $]^{53}$.

En este segundo viaje a Canarias, Torriani obtuvo un mayor poder de actuación, contando con unos 40 ducados de salario mensual, más 300 ducados para los gastos derivados del largo viaje a las islas ${ }^{54}$. Así, Torriani regresó en primer lugar otra vez a La Palma en fecha de 20 de agosto de $1587^{55}$, donde continuó con su proyecto del puerto de Santa Cruz de La Palma, además de visitar aquellos lugares necesitados de construcciones defensivas militares ${ }^{56}$.

En las jornadas que Torriani dedicó a la visita del lugar, observó una isla orográficamente muy escarpada, lo cual resulta, en su opinión, una ventaja por la protección natural de todo el litoral, a excepción de la capital insular. Así, existen dos playas en la línea costera capitalina que a su juicio eran ampliamente vulnerables y, de hecho, por ellas desembarcó la tripulación de Pie de Palo e intentaron hacerlo los británicos, con Francis Drake al mando ${ }^{57}$. En primer lugar, Torriani abogaba por fortificar la playa que se encuentra en la zona de La Caldereta, denominada Bajamar, lo cual aseguraría toda la costa hasta el castillo de Santa Catalina. Por otro lado, la otra zona vulnerable de la ciudad se encontraba en El Cabo, donde existe una torre, pero la intención de Torriani era fortificarla de una manera más eficiente, mejorando sus trincheras y bastiones que, como decíamos, ya se encontraban construidos ${ }^{58}$.

Ciertamente, y a pesar de los intentos de Torriani por la mejora del sistema defensivo palmero, más la construcción del puerto de Santa Cruz de La Palma, lo cierto es que a su partida de la isla, en el año 1587, se llevó consigo una gran animadversión de ella y de sus gentes, máxime cuando las tensiones suscitadas por el ninguneo al que se vio sometido por parte del Cabildo palmero se generaron en torno a los continuos problemas que las autoridades insulares le brindaron al ingeniero italiano, torpedeando el correcto avance de las obras y planos al ritmo que, con la ayuda cabildicia, se podrían haber desarrollado ${ }^{59}$. En su Descripción de las islas Canarias llegó a calificar al gobierno de la isla de «jóvenes escolares de pocas letras, los cuales gobiernan a su antojo, atendiendo antes a sus intereses y a sus amoríos, que al beneficio de la república» ${ }^{60}$.

Torriani llegó, incluso, a elevar una carta a Felipe II presentando sus quejas sobre los enormes inconvenientes encontrados en el desarrollo de su trabajo. En concreto, las demandas del ingeniero cremonés con respecto al gobierno insular pasaban por dotarle de una serie de subordinados para la construcción, el acompañamiento de algún regidor a la visita de las fortificaciones y un informe sobre las posibilidades económicas del Cabildo para abordar los gastos de las defensas militares ${ }^{61}$. Parece muy probable que la animadversión de la corporación insular hacia Leonardo Torriani (y que también se fue desarrollando con respecto a la Justicia y Regimiento del Cabildo de Tenerife por otras razones) se produjo por las órdenes expresas de Felipe II de enviar toda la información en cuanto a fortificaciones directamente a la Corte real, aspecto que generó una gran desconfianza de las instituciones insulares con el ingeniero cremonés $^{62}$.

Próspero Casola, discípulo de Torriani, en La Palma

53 Real Cédula de 20 de mayo de 1587 en RUMEU DE ARMAS (1991), Tomo II, Primera parte, 377.

54 TORRIANI (1959), Introducción, p. 18.

55 TORRIANI (1959), Introducción, p. 19.

56 MARTÍN RODRÍGUEZ (1986), p. 24.

57 TORRIANI (1959), p. 245.

58 TORRIANI (1959), p. 247.

59 FERNÁNDEZ (2001), p. 71.

60 TORRIANI (1959), p. 243.

61 MARTÍN RODRÍGUEZ (1986), p. 25.

62 MARTÍN RODRÍGUEZ (1986), p. 37. 
La llegada de Casola a Canarias no está del todo aclarada hasta ahora, pues mientras unos autores como Rumeu y Tous afirmaban que llegó a las islas coincidiendo con el nombramiento de don Luis de la Cueva y Benavides como capitán general y presidente de la Real Audiencia, formando parte de su séquito como criado y auxiliar de las fortificaciones, otros, entre ellos Viera y Clavijo, aventuran su llegada a 1587. Pues bien, esta duda nos la disipa el propio Próspero cuando dice en uno de sus escritos que, estando en Madrid estudiando matemáticas y habiendo proveído que Leonardo Torriani pasase a las Canarias para fabricar un muelle ${ }^{63}$ en la isla de La Palma, dada la importancia de su actividad comercial, en especial por el trasiego mercantil de la flota de Indias, aprovechándose para ello del estatuto dictaminado por el rey, vino a las islas por ayudante suyo, pues:

El año de mil y quinientos y ochenta y siete que vuestra magestad embió a estas yslas Leonardo Turriano a reconocer las fuerças y a hazer la descripción dellas... me persuadió el dicho Leonardo Turriano le acompañasse y le fuesse a ayudar en aquel trabajo, salí de la corte sin salario de vuestra magestad y suio... ${ }^{64}$.

Añade que acompañó al ingeniero para visitar las fuerzas, sacar las plantas y hacer la descripción de ellas. Además, Próspero asegura en uno de sus escritos que estuvo en Gran Canaria al servicio de don Luis de la Cueva todo el tiempo que aquel estuvo como gobernador y capitán general del archipiélago, pues reconoce que al cabo de dos años de estar en las islas, esto es, en 1589, llegó a ellas don Luis con el presidio "e como e sido siempre amigo de la virtud" estando de camino para Italia, de donde era natural, le propuso para que sirviese al rey al conocer las plantas que había sacado y la descripción que de su mano había hecho de las islas.

Por ello no es de extrañar el conocimiento que el ingeniero muestra de la isla de La Palma, aunque tampoco es óbice dadas las veces que tuvo que acudir a ella en compañía de los generales que hacían la visita reglamentaria de las fortificaciones. Al menos, en función de la información que tenemos, hay constancia de hasta tres visitas a La Palma: una con don Luis de la Cueva; otra, en 1620; y la que hizo junto con el capitán general don Iñigo de Brizuela.

La atención de Próspero en esta isla se centra en dos zonas: Santa Cruz de La Palma y Tazacorte. Sobre ambos lugares hace la descripción pertinente, aunque, como es natural, centra toda su atención en los aspectos que tienen que ver con las fortificaciones.

En Santa Cruz de La Palma su atención se fija en el muelle, donde él había colaborado junto con Torriani a partir del año 1587, a la vez que hace mención a los tres castillos o fortalezas que estaban levantados en la costa de la ciudad a fines del siglo XVI. Del muelle comenta que su fábrica se había hecho en el año de 1586 por orden del rey y de la Real Hacienda, y que en la época en que lo visita, para su enfado, estaba medio arruinado, por lo cual plantea que sería conveniente ensancharlo y alargarlo más en dirección al mar a fin de que se formara un ángulo para facilitar el desembarque desde los navíos y asegurar el muelle.

En cuanto a las defensas que tenía la ciudad, enumera las mismas recogidas en el inventario que hizo en 1599 el licenciado y juez de Indias Juan Casal: el baluarte de San Miguel, el de Santa Catalina y el que llamaban de Santa Cruz o del barrio del Cabo.

La ciudad de la isla de La Palma esta travesada de hueste sueste tendida por la costa de la mar junto de la qual tiene tres fortaleças para su defensa, la primera sobre el Puerto Prinçipal en forma de torre exagonal con plaça descubierta, la qual por estar algo metida dentro a las casas descubre con dificultad la plaia hazia el fuerte de Sancta Catalina sirve para defensa de los navíos que surgen en el dicho puerto conviene acrecentarlo quarenta pies hazia el muelle y añadirle dos culebrinas de alcance para asegurar mejor los dichos navios y se excusara la nueva fortificación que se trata de hazer en el sitio de la Caldereta y punta de baxamar pues con ella se assegura la playa y punta de baxamar y se viene a horar todo el costo del castillo de la punta de baxamar y la obligación de sustentarlo de Artillería, armas, municiones, soldados y artilleros que lo an de guardar que para un cosario o dos es mucha obligación y gasto y en el

63 El muelle de Santa Cruz de La Palma fue iniciado por Leonardo Torriani y era el único que merecía ese nombre en el archipiélago. RUMEU (1991), Tomo II, Primera Parte, p. 323.

64 LOBO y BRUQUETAS (2014), p. 43. 
ynterín y mientras se procuran las dos culebrinas se puede sacar una del fuerte de Santa Catalina y pasar al dicho fuerte del puerto ${ }^{65}$.

El primero de ellos, el de San Miguel se hallaba situado a la entrada de la ciudad, en la plazuela del muelle. Según Próspero era de forma hexagonal con plaza descubierta, la cual estaba un poco metida entre las casas y generalmente tenía como una de sus funciones servir de defensa a los navíos que surgían en las cercanías del mismo. Para el ingeniero era recomendable acrecentarlo unos cuarenta pies en dirección al muelle y añadirle artillería de alcance con el fin de asegurar mejor los navíos que fondearan en el puerto.

El segundo fuerte y mayor era el de Santa Catalina, el cual se acordó hacer después del asalto de 1553 en el barrio de su nombre, que se comenzó en 1554 y se culminó en 1560 . Este estaba en el extremo de la ciudad, era de forma ovalada y en medio tenía una torre redonda que ocupaba parte de la retirada de la artillería; en dirección a la ciudad contaba con su foso fuerte y puente levadizo. Recomendaba Próspero que se derribara la torre, a la vez que se reparasen los cimientos en la zona cercana al mar porque mostraban ruina; además recomendó hacerle una contra muralla de cal y cantos que estuviera bien tupida y encalada. De acuerdo a la situación en que se encontraba, cuando hace la visita recomienda:

Tiene necesidad este fuerte de reparar a la parte de la mar los cimientos porque muestran gran ruina, haziéndole una contra muralla de cal y cantos bien encaladas las juntas y si se le hiziera la plaizada que antiguamente solía tener de vigas y gruessos tablones sería gran reparo para la dicha fábrica.

La muralla que comiença deste dicho fuerte y va a acavar al pie del risco es necesario conservar y reparar de lo necesario y conservar hasta al pie del risco y fortificar de manera que el enemigo no pueda entrar por aquella parte, la puerta de la dicha muralla se a de reparar de todo lo necesario ${ }^{66}$.

El tercero, llamado del barrio del Cabo, estaba situado próximo a la entrada norte de la ciudad y al parecer había sido construido en 1568. Este fuerte tenía plaza rectangular y estrecha, y su función dejaba bastante que desear; no obstante, planteaba el ingeniero que se restaurasen los cimientos y se conservase la muralla que iba desde este fuerte hasta el risco, de modo que el enemigo -en caso de desembarcar por aquel sitio- no pudiese entrar en la ciudad. A la vez indicaba que fácilmente se podía fortificar y guardar con 200 hombres, tal como lo señala en escrito remitido al Consejo de Guerra:

El tercero fuerte es el que llaman barrio del Cavo está fundado fuera de la ciudad con plaça retangular y estrecha guarda flacamente una desembarcaçión y playa muy cumplida, fuera de grande importancia si se ensanchase y se hiziese capaz de mas pieças de artillería y mientras no se haze esto será bien acudir a los cimientos que están caydos y se van cayendo y abriendo la muralla de alto abaxo del dicho fuerte y a el hazer lo mesmo que se manda hazer al fuerte de Sancta Catalina ${ }^{67}$.

Después de describir y recomendar lo que debía hacerse con las fortalezas de la ciudad, proponía al Consejo de Guerra hacer una nueva fortificación en la Caldereta, a la salida de la ciudad, ya proyectada por Torriani con anterioridad, para asegurar la playa y punta de Bajamar, siempre que se sustentara con artillería, armas, municiones y soldados. De este sitio destacó el arte que la propia naturaleza le había prodigado en su emplazamiento, a la derecha de la ciudad y un poco fuera de ella, donde se encontraba un eminente y espacioso llano conocido con el nombre de la Caldereta, desde el cual se señorea el mar y la tierra, tal como lo deja señalado en los informes que envía a la Corona:

65 Archivo Casa Condal de la Vega Grande de Guadalupe, Carpeta Próspero Casola, sin numerar.

66 Archivo Casa Condal de la Vega Grande de Guadalupe, Carpeta Próspero Casola, sin numerar.

67 Archivo Casa Condal de la Vega Grande de Guadalupe, Carpeta Próspero Casola, sin numerar. «La orden que se ha de tener en fortificar la ciudad de la ysla de la Palma y su contorno». 
Ay un eminente llano y espaçioso que se llama la caldereta que está menos sujeto que los demás de la ciudad el qual señoreando mar y tierra bate la ciudad el puerto que le está debaxo y la dicha playa de Baxamar que del pie del se comiença a estender del que se deve de hazer mucho caso por ser fuerte por naturaleza y común a tres defensas y se deviendo de fortalecer para asiento de artillería y guarda de munición por las razones dichas y aunque por su altura y estar lexos de la dicha plaia sus tiros serán de mucho provecho contra los navíos gruessos que quisieren surgir y llegarse a tierra para batir las trincheas e limpiar la plaia de la defensa con su artillería y combendría se fortificasse la dicha plaia ${ }^{68}$.

En Tazacorte existían dos pequeñas fortificaciones o fortines, que debieron de construirse a lo largo del siglo XVI por los propietarios de los ingenios azucareros de la zona, tanto los Monteverde como los Van Dale. Los mismos no solo se contentaron con su construcción, algo rústica al decir del ingeniero, sino que los artillaron para asegurar la carga y descarga de mercancías en la zona y, especialmente, de los azúcares que producían los ingenios. Uno de los fortines estaba situado en la desembocadura del barranco de Tinisquey y el segundo, en la boca del barranco de las Angustias.

Dichas fortificaciones fueron visitadas por don Luis de la Cueva y Benavides, y es posible que fuera precisamente en esa visita cuando Próspero tomó sus apuntes que constan de un boceto de plano y algunas notas sobre ellos. De la que estaba en el puerto señala su ubicación y la longitud de su playa así como las dos plazas acomodadas para artillería. Una estaba a mano derecha dispuesta con quince pies de alto y fábrica de cal y cantos, con sus paredes. El pavimento estaba enlosado y además disponía de una casa de municiones y alojamiento, donde se ubicaban cuatro piezas de artillería de hierro colado con el objeto de defender los navíos que se guarecían a su sombra. La otra fortificación se ubicaba al final de la playa, a mano izquierda, fabricada de piedra seca sobre un "risquete", donde estaban puestas dos piezas de artillería de hierro con la que ayudaba a la otra plaza. Convenía su defensa por ser el sitio donde se embarcaban los frutos de los dos ingenios de azúcar que estaban en sus cercanías, muy ricos «y de bondad no se sabe que aya otros mejores de su grandeça, y se estiman en quatroçientos mil ducados», que era en lo que consistía la mayor riqueza de la isla ${ }^{69}$.

\section{Principales fuertes de SANTA CRUZ de la Palma}

La situación geográfica de Santa Cruz de La Palma se convirtió en un punto vulnerable por donde se podían hacer entradas sin gran dificultad, por lo cual el Cabildo siempre tuvo preocupación por fortificar el litoral, especialmente a partir de los conflictos que se libraban en Europa entre la Corona hispana y las distintas potencias europeas.

Estas razones hicieron que tanto las autoridades isleñas como las hispanas tuvieran en mente proteger la ciudad y la isla de los ataques externos, dada la debilidad de las fuerzas que tenía la isla, tal como señala Viera y Clavijo cuando comenta que las fortificaciones de La Palma en el siglo XVI eran débiles ${ }^{70}$.

De hecho, la defensa se convirtió en una obsesión, aunque la Corona se tomó su tiempo en intervenir de manera directa con el envío de ingenieros militares que emitieran informes sobre la situación de la defensa de las islas Canarias.

El retraso en la toma de decisiones por parte de la Corona hizo que el Cabildo palmero tomara la iniciativa, a pesar de que tanto el armamento como las obras necesitaban de capitales y los recursos del consistorio siempre fueron escasos, de ahí que así todo el Cabildo con el apoyo de las autoridades insulares iniciara su propio plan construyendo desde bien pronto una de sus principales defensas, junto al desembarcadero, con el fin de proteger a los navíos que mantenían la actividad mercantil de la isla con el exterior. Las distintas actas de los acuerdos

68 Archivo Casa Condal de la Vega Grande de Guadalupe, Carpeta Próspero Casola, sin numerar.

69 Archivo Casa Condal de la Vega Grande de Guadalupe, Carpeta Próspero Casola, sin numerar: «Relaçión del Puerto de Taçacorte y su fortificación».

70 VIERA Y CLAVIJO (1967), Tomo III, Libro 13, p. 117. 
tomados en el Cabildo dan cuenta de la preocupación de la ciudad por las defensas, tal como acontece en una sesión del año 1550 ya referida anteriormente ${ }^{71}$.

El ataque francés a Santa Cruz de La Palma vuelve a poner sobre el tapete la escasa defensa que tiene la isla, de tal modo que en las primeras actas del Cabildo acordadas después de 1553, se muestra la gran preocupación de los munícipes por la vulnerabilidad de la costa palmera.

El año 1554 es un año decisivo en la toma de decisiones de tal modo que el gobernador de las islas de Tenerife y La Palma, el licenciado Juan López de Cepeda, acude a La Palma en dos ocasiones para tomar las riendas de la defensa organizando en primer lugar las milicias como paso previo para poner en orden la defensa ${ }^{72}$. A continuación se está a la búsqueda de armamento, tanto en la Península como en otras partes, puesto que la escasez de equipamiento bélico era una de las razones más comentadas en los cabildos de la segunda mitad del siglo, especialmente durante el reinado de Felipe II. Así la solicitud de armas al Consejo de Guerra se reitera en varias ocasiones tal como acontece en los años 1554, 1555, 1557 1558, 1561, 1573 y $1578^{73}$.

\section{Torre de San Miguel}

Esta defensa fue la primera que se construyó en la isla. Su ubicación se situó en una zona clave para la ciudad, junto al puerto, para defender y dar cobijo a los navíos que surgían a su sombra, y su advocación tiene que ver con el patrón de la isla, San Miguel. La importancia de este puerto, el principal de La Palma, se observa también en las ordenanzas municipales, donde se manda que ningún navío ni barco surja en puertos de la isla fuera de la ciudad ${ }^{74}$.

El inicio de su construcción tiene relación con una misiva real recibida en 1512, coincidente con los primeros enfrentamientos que se mantienen con Francia ${ }^{75}$. La obra comienza en estos primeros años porque ya en 1515 se da por concluida, gracias a la recaudación del quinto de las cabalgadas a Berbería, que los reyes otorgaron a las islas, y de las penas de cámara. El Cabildo con ambos impuestos aportó 250 ducados y nombró a su primer alcaide, por lo que levantan así el primer baluarte que se conoció en la costa de la ciudad.

Conseguida la torre, ahora era necesario artillarla y para ello se obtuvieron unos 600 ducados en 1524, gracias al sistema de reparto entre los vecinos ${ }^{76}$. Gobernando Carlos V, en 1528 se le concede una cédula real a la isla para que el Cabildo pueda estimar la cantidad que se van a recaudar; años más tarde gracias al impuesto de la sisa del vino, aprobada por el consistorio, se ayuda al alcaide para que pague a los artilleros y a su vez invierta algunos ducados en las reparaciones necesarias ${ }^{77}$.

Después de ataque de François Le Clerc, "Pie de Palo", la torre que poco daño hizo al enemigo, en parte por ser la única y con escasa artillería, es remodelada y reforzada, en especial después de las iniciativas tomadas por el licenciado Cepeda, gobernador de la isla, quien la describe «pequeña, inútil y sin ninguna maña para la defensa» ${ }^{78}$. Asimismo, era notorio que cuando la ciudad fue asaltada por los franceses se hizo mucho daño por la falta de armas que en ella había ${ }^{79}$.

Por estas razones, a partir de 1553 el cabildo no solo proyectó mejorarlo, sino que le añadió un terraplén abaluartado o batería por la parte delantera, gracias a la aportación de los vecinos. Así en el año de 1554 se manda buscar cal a Tenerife para reforzar el terraplén ${ }^{80}$, y se continúan las obras gracias a la aportación de la Corona y al repartimiento de 3000 ducados que se hace

71 MARTÍN RODRÍGUEZ (1995), p. 198

72 HERNÁNDEZ MARTÍN (2000), p. 24.

73 En el Archivo de Simancas y en la sección Guerra y Marina, en distintos legajos figuran las peticiones de artillería de la isla de La Palma al Rey.

74 LORENZO RODRÍGUEZ (1987), p. 416.

75 AZNAR VALLEJO (1983), p. 52.

76 AZNAR VALLEJO (1983), p. 52.

77 RUMEU DE ARMAS (1991), Tomo 2, 1ª parte, p. 235.

78 PINTO DE LA ROSA (1996), p. 363.

79 MARRERO, SOLANO y DÍAZ (2005), Introducción, p. 27.

80 MARRERO y otras (2005), Acta de Cabildo de 6 de marzo de 1554. 
entre los vecinos ${ }^{81}$. El objetivo a perseguir con estos recursos era reforzar la torre hexagonal con terraplén abaluartada, que permitiese por un lado aumentar su capacidad para acoger a la población y las vituallas necesarias en caso de ataque, y además poder artillar la fortaleza de manera más efectiva.

El licenciado Juan López de Cepeda, en un escrito que envía al rey en 1554, da cuenta de la situación en que se encuentra la fuerza de la ciudad junto al puerto; así en la descripción que hace de la misma dice:

La fortaleza que está junto al puerto tiene una torre alta y junto a ella un terraplén más bajo de pared bien gruesa de piedra de barro y cal, el cual dicho terraplén tiene una plazeta buena empedrada donde pueden estar las piezas de artillería, que tiene un pretil fuerte con sus troneras por donde se pueden servir las piezas gruesas de artillería que en la dicha fortaleza estuviesen y en la dicha torre está otra plazeta con otro pretil donde asimismo puede servir la artillería $^{82}$, consiguiendo con ello ampliar la capacidad de defensa de la fortaleza.

Estas obras, gracias a la aportación tanto de la Corona como de los vecinos, se realizaron con cierta celeridad, de tal modo que en el año de 1555 se consideraba que ya estaban concluidas. Hasta tal punto se estimaba la buena disposición de la fuerza que en al año siguiente, en 15 de abril de 1556 en carta que Juan de Monteverde remite a los señores del Consejo de Guerra, da cuenta de en qué estado se encontraba, «que en el puerto hay una fortaleza con un terraplén... donde están veinticinco piezas de artillería de hierro y un cañón de metal que es defensa que basta para el dicho puerto» ${ }^{83}$.

Los primeros alcaides que tuvo la torre figuran en la nómina a partir de 1515. Ese año era castellano el regidor Vasco Baamonde, nombrado por el rey Fernando el Católico. En 1516 el repostero del emperador Pedro de Rada, nombrado por Real Cédula fechada en Bruselas en mayo de 1517, figura como castellano de la torre del puerto. A partir de 1568 a través de otra cédula real se estipula que el cargo de alcaide recaiga en persona principal, en la mayor parte de los casos dentro del grupo de los privilegiados, nombrada por el cabildo de la isla, y cuyo mandato se establece en dos años, orden que permite desposeer al capitán general Juan de Monteverde de su cargo. A partir de aquí el Cabildo tenía el privilegio de elegir en enero de cada año, con autorización real, los alcaides de las fortalezas.

\section{La Fortaleza de Santa Catalina}

La información sobre la fortaleza de Santa Catalina es más abundante, quizá por la propia información que se genera a partir de su construcción y especialmente por las acciones llevadas a cabo por el capitán general Juan de Monteverde ${ }^{84}$.

A la par que se toma en consideración por el Cabildo la remodelación y ampliación de la torre de San Miguel, se idea la construcción de otra fortaleza ubicada al norte de la ciudad en el barrio de Santa Catalina, que se considerará a partir de esta fecha como la principal fuerza de la isla, tanto por su ubicación como por su posición estratégica al permitir defender a la ciudad tanto por la parte de la marina como de tierra ${ }^{85}$. El nuevo fuerte ocuparía el saliente formado por la costa y el barranco de Santa Catalina en que terminaba la población por la zona norte. Por tanto, la construcción de esta fuerza tiene lugar después del ataque sufrido en la capital por los franceses. Así a petición de la ciudad, el príncipe Felipe por Cédula fechada en Valladolid el 8 de abril de 1554 concede facultad al Cabildo para que se hiciera un reparto de 6.000 ducados,

81 RUMEU DE ARMAS (1991), Tomo 1, $2^{\mathrm{a}}$ parte, pp. 180-182.

82 MARTÍN RODRÍGUEZ (1995), p. 200; PINTO DE LA ROSA (1996) p. 363.

83 Archivo de Simancas, Mar y Tierra, legajo 62. Carta de Juan de Monteverde a los muy poderosos señores del Consejo de Guerra (15 de abril de 1556).

84 Además de lo que aporta RUMEU DE ARMAS (1991) Y MARTÍN RODRÍGUEZ (1995), son interesantes los dos artículos que publica DARIAS PADRÓN, D.V., en el periódico La Tarde, Santa Cruz de Tenerife, 13 y 16 de octubre de 1942.

85 PINTO DE LA ROSA (1996), p. 343. 
3.000 entre los vecinos, al haber quedado la ciudad totalmente desmantelada tras el ataque ${ }^{86}$, destinados a la construcción de dos fortalezas en la ciudad de Santa $\mathrm{Cruz}^{87}$.

No obstante, el origen de la iniciativa de esta construcción, que se inicia en mayo de 1554, se toma en una reunión convocada por el gobernador Cepeda en la iglesia de El Salvador, donde se decide repartir los gastos de la construcción entre los vecinos de la isla ${ }^{88}$. Al estimarse que el costo de la obra podía llegar a ascender hasta los 6.200 ducados, se considera oportuno solicitar al rey la mitad y la otra mitad repartirla entre los vecinos

En esta fecha, tal como se colige de las actas capitulares, se había nombrado como jefe de la milicia y como capitán general de la isla y alcaide de las fortalezas a Juan de Monteverde ${ }^{89}$, al cual el gobernador consigue comprometerlo, en el momento en que toma posesión de cargos tan importantes, de que costee la nueva obra, aunque él aclara que preferiría costear una nueva construcción defensiva, que se haría en La Caldereta.

Finalmente se llega a un acuerdo entre Juan de Monteverde y el Cabildo, tal como queda reflejada en una de las actas de consistorio en estos términos:

...e así se concertó entre la ciudad y el dicho Juan de Monteverde e por ambas las partes fueron nombradas terceros que fueron los señores Baltasar de Fraga e Miguel Lomelin regidores desta ysla para que apreciasen lo que el dicho Juan de Monteverde podría gastar y le costaría en la fortaleza que avía de hazer en la caldereta para que lo que ellos dixe sea y tasasen lo gastase el dicho Juan de Monteverde aprovó y tuvo por buena y por un escrito que presentó ante el Licenciado Cabrera, seyendo teniente de gobernador desta ysla, y en presencia de Sancho de Urtate, escribano público, en veynte y seis días del mes de setiembre del año que paso de mile e quinientos e cinquenta e cinco que está firmado de su nombre dixo que demás e abiendo de las mile y dozientas doblas en que los dichos terceros avían tasado los dichos gastos que abía de hazer en la dicha fortaleza él se ofrecía y ofresció de pagar otras seiscientas doblas más para la obra de la dicha fortaleza de Santa Catalina que sea por todas mile y ochocientas doblas como parece por el dicho auto judicial que hizo y otorgó... ${ }^{90}$.

En ese año se comienzan a levantar los muros con tal rapidez que el torreón o cubelo central ya está levantado hasta la altura de las troneras por el mes de agosto, gracias a la cantidad de personas que participan en la construcción y al gasto realizado que entre julio y agosto ascendía a algo más de 100.000 maravedís $^{91}$, de tal modo que a finales del mes de octubre de 1554 el teniente de gobernador de la isla informa que la obra del cubelo y fortaleza que se hacía abajo del barrio de Santa Catalina «es cosa muy importante acabar en breve» ${ }^{92}$.

Posteriormente, en escrito remitido por el gobernador Cepeda al Consejo el 15 de mayo de 1557 describe el cubelo como bueno, grande y fuerte, tal como lo había dejado y trazado cuando abandonó La Palma, con lo cual la ciudad quedaba defendida por dos fuerzas que resguardaban tanto a la urbe como al puerto ${ }^{93}$. Esta es la razón por la cual el cabildo insiste en solicitar artillería para esta fortaleza y la del puerto al considerar que la ciudad tiene «ya hechas fuerças a costa de los vecinos» ${ }^{94}$, donde podía estar segura la artillería.

En 1559, fecha en que el visitador Alonso Pacheco gira ronda a la isla se informa de que las obras de Santa Catalina estaban casi concluidas, que se dieron por acabadas en $1560^{95}$, pues de este modo quedaba defendida por aquel lado la ciudad de los desembarcos que los enemigos hacían por aquella zona.

86 PINTO DE LA ROSA (1996), p. 370.

87 NÚÑEZ y otros (1999), T.I, p. 169.

88 SÁNCHEZ RODRÍGUEZ (1953), pp. 131-134.

89 Según Rumeu, muchos de los regidores del Cabildo de La Palma se mostraron contrarios al nombramiento de Monteverde como capitán general de la isla debido, entre otros aspectos, a su naturaleza extranjera. Esta situación generó un amplio pleito legal que culminó con la sentencia de la Real Audiencia en 1556 a favor de Monteverde, quien ocupó el cargo de capitán general hasta su fallecimiento en 1568, a pesar de las sucesivas protestas posteriores de los regidores al Consejo de Guerra. RUMEU DE ARMAS (1946), pp. 12-16.

90 AMSCLP, Libro de Acuerdos del Cabildo 1559-1567, Acta del día lunes 27 de octubre de 1561.

91 MARRERO y otros (2005), Acuerdo de Cabildo del 16 de agosto de 1554.

92 MARRERO y otros (2005), Acuerdo de Cabildo de 29 de octubre de 1554.

93 MARTÍN RODRÍGUEZ (1995), p. 205.

94 MARRERO y otras (2005), Acuerdo del Cabildo de 14 de febrero de 1556.

95 PINTO DE LA ROSA (1996), p. 379. 
Después de este informe, en 1559 se proyecta en la fortaleza un terraplén de 200 pies a su alrededor en forma de media luna, con el fin de evitar los embates del mar, dada su cercanía a la costa, que lo levanta 35 pies. En 1560 ya está la fortaleza concluida, aunque todavía se siguen recabando materiales como, por ejemplo, $\mathrm{cal}^{96}$.

Al final resultó ser una importante fortificación de planta casi elíptica, en cuyo centro se hallaba un cubelo cubierto. Los muros exteriores eran de sillería soportada con contrafuertes, totalmente terraplenada y cubierta de losetas para formar la plaza de armas. El cubelo central era todo de sillería con sus troneras, de dos plantas, el cual servía de alojamiento al alcaide y soldados de la guarnición.

No obstante, en 9 de septiembre de 1561 se estima que a pesar de lo reciente de su construcción la fortaleza de Santa Catalina se encontraba algo deteriorada por lo cual el alcalde mayor reclamaba a sus compañeros de consistorio que convenía «le podría venir mucho daño si no se remedia por tanto que pide y requiere a los señores regidores den horden y provean como se remedie y cobije» ${ }^{97}$.

Al año siguiente, 1562, el pleno del Cabildo encarga a Domingo García que se haga reparar el terraplén de la fortaleza de Santa Catalina todo lo que fuere necesario ${ }^{98}$, y meses más tarde se acuerda que en el baluarte del terraplén de Santa Catalina se haga un contrabaluarte ${ }^{99}$.

El jueves 15 de octubre de 1562, con el objeto de comprobar las obras de la fortaleza el Cabildo en pleno se reunió y trató varios asuntos en sus dependencias ${ }^{100}$. Después de las visitas que los miembros del Cabildo solían hacer a las distintas fuerzas de la ciudad en viernes 2 de julio de 1563, se acuerda por los munícipes que el terraplén de Santa Catalina se enlose de piedra llana para que la artillería pudiera jugar ligeramente y no tuviera ninguna obstrucción, por lo cual se encomienda al teniente y al regidor Luis Álvarez que tal obra se concierte con el cantero Manuel Días u otro oficial que la haga ${ }^{101}$. Distintas obras se siguieron haciendo en los años siguientes, especialmente aquellas que tenían que ver con reparaciones, habilitamiento para la artillería, la ejecución de candados y la compra de una campana ${ }^{102}$.

En 1568 todavía quedaban algunas cosas pendientes en las obras de reparos y mantenimiento de la fortaleza, razón por la cual el nuevo alcaide, el regidor Miguel Lomelín, informaba al Cabildo de cómo el regidor Hernando de Villalobos había prestado para la fortaleza 1.600 tejas ${ }^{103}$.

En el año de 1569, en 22 de abril, se trata en una sesión de Ayuntamiento el ampliar algunas partes del fuerte. Así entre los distintos capítulos que se discuten, uno propone que se hagan dos troneras a cada lado de la fuerza:

En quanto al primero capítulo que se pide a lleven a - las dos - de los lados del terrapleno se a sido que se hagan como dos troneras de cada parte y si les pareciere que una basta haga una y llegue la pared hasta el lugar que les paresciere a los señores Miguel Lomelin y Nicolas Ortes, regidores, a quien se cometió que lo hagan hazer y tomen la cal que fuere menester de la que tiene la ciudad y se pague de ynpusición y los oficiales y todo lo demás que fuere necesario se

96 AMSCLP, Libro de Acuerdos del Cabildo 1559-1567, Acta del día lunes 27 de octubre de 1561. En acta de martes dos de diciembre de 1561, se da cuenta de que Antonio Gómez, artillero que había sido de la ciudad había dado razón de los cien cahices de cal que el pedrero Hernán Báez era obligado a dar la ciudad por las 200 doblas que se le dieron y se gastaron en la obra de la fortaleza.

97 AMSCLP, Libro de Acuerdos del Cabildo 1559-1567, Acta del día martes 9 de septiembre de 1561.

98 AMSCLP, Libro de Acuerdos del Cabildo 1559-1567, Acta del día lunes 20 de julio de 1562.

99 AMSCLP, Libro de Acuerdos del Cabildo 1559-1567, Acta del día 14 de septiembre de 1562.

100 «Este dia se juntaron a cabildo el magnífico señor bachiller Francisco Espino, teniente de gobernador desta ysla y los señores Miguel Lomelin y Guillen Lugo de Casaos y el bachiller Juan Espino, Luis Álvarez y Baltasar Pérez, regidores de la dicha ysla y el señor Licenciado Francisco de Loreto, fiel executor con boz y boto en este cabildo y Francisco Pérez jurado de la dicha ysla por presencia de nos, Pedro de Belmonte e Diego de Chaves, escribanos del cabildo de la dicha ysla y se juntaron en la fortaleza de Santa Catalina». AMSCLP, Libro de Acuerdos del Cabildo 1559-1567, Acta del día 5 de octubre de 1562.

101 AMSCLP, Libro de Acuerdos del Cabildo 1559-1567, Acta del día viernes 2 de julio de 1563.

102 AMSCLP, Libro de Acuerdos del Cabildo 1559-1567, Acta del día 26 de marzo de 1565 y Acta del día 1 de junio de 1565 .

103 AMSCLP, Libro de Acuerdos del Cabildo 1567-1570, dado que la fecha del acta está ilegible, deducimos que se trata de un acuerdo entre el 9 y el 23 de julio de 1568. 
pague de las seys mil doblas que su magestad mandó echar por ynpusición para las municiones y reparos de la fortaleza, y lo hagan haser con toda brevedad ${ }^{104}$.

La necesidad de continuar las obras y fortificar mejor a la ciudad hizo que a petición de la isla el rey Felipe II, por Cédula fechada en 5 de agosto de 1577 concediese a su cabildo licencia para poder navegar a las Indias bien desde Cabo Verde como de Guinea 500 piezas de esclavos negros, la tercera parte hembras, para que lo obtenido se invirtiese en las fortificaciones de la isla y especialmente en la reparación y edificación de un muelle ${ }^{105}$.

En 1585 el castillo de Santa Catalina contaba con 10 piezas de artillería, cuando era alcalde de la fortaleza Pedro Hernández Señorino.

El alcaide de Santa Catalina era el único que disfrutaba de sueldo o salario anual, en principio de 50 ducados, y luego llegó a 100 por Real Cédula de 28 de enero de 1586, la mitad de los propios y la otra mitad de las penas de cámara.

La alcaldía de esta fortaleza junto con la del puerto la usufructuaba desde el momento de su construcción Juan de Monteverde ${ }^{106}$, como capitán general hasta 1567, fecha en que el Cabildo recabó poder efectuar el nombramiento del alcaide como sucedía en Tenerife y Gran Canaria. Además de aportar parte de su peculio a la construcción de esta fuerza con el tiempo el cabildo le fue asignando otras obligaciones, que a veces no cumplía, en especial en los momentos de alarma por la posible presencia en aguas canarias de corsarios y piratas tanto franceses como de otros partes de Europa, especialmente luteranos, tal como se comprueba en algunos de los acuerdos capitulares, así en 10 de mayo de 1563 el Cabildo ordenó que:

Juan de Monteverde, capitán general desta ysla viviese en la fortaleza de Santa Catalina y asistiese en su oficio y hiziese lo que más convenía al servicio de su magestad que para todo estaba presto de le dar favor e ayuda e hizo ciertas informaciones e le entregó juntamente con dos caballeros del cabildo cantidad de pólvora a su contento e se pregonó que los que tuviesen armas las traxesen a listar e visitar ayer Domingo e yendo a ello vio que el dicho Juan de Monteverde no asistió a la lista ni vive en la torre ni la tiene reparada ni limpia ni hordenada la artillería e munición como conviene... ${ }^{107}$

Estuvo como alcaide desde 1554 hasta 1567 y le sucedió Miguel Lomelin, el cual fue propuesto por el cabildo para que tuviera todo el recaudo necesario de las piezas y municiones de las fortalezas de la ciudad.

En 17 de febrero de 1568 el regidor Miguel Lomelin comparece ante el cabildo como alcaide de las fortalezas de la isla, nombrado por el rey y por los señores de la Audiencia, a propuesta del Concejo, y como tal considera que a él le corresponde hacer el nombramiento de los lombarderos de las fuerzas de defensa, tal como lo hacía Monteverde por provisión de la Audiencia y de acuerdo con los miembros del consistorio propuso para el desempeño de tal oficio al flamenco Andrés Lorenzo, por ser persona hábil y suficiente, obligado a residir con su casa y mujer en las fortalezas ${ }^{108}$. Al año siguiente con el parecer del alcaide se contrató como lombardero a un portugués, Nuno Hernández, hombre hábil y suficiente ${ }^{109}$.

Asimismo correspondía al alcaide la fortaleza de Santa Catalina, dado el volumen de trabajo al tener que atender a todas las fuerzas de la ciudad, de nombrar a una persona, la que más conviniese para que asistiese a la fortaleza del puerto, ya que, como era obligación del alcaide residir en la fortaleza principal de Santa Catalina, se considera oportuno que dicha persona residiese en la otra fuerza, siempre y cuando fuese aprobado su nombramiento por el cabildo ${ }^{110}$.

En 3 de septiembre de 1579 figura como nuevo alcaide de las fortalezas de la isla el regidor Juan Alarcón ${ }^{111}$, el cual solicita al Cabildo que se dé la posesión de la tenencia del cargo, así

104 AMSCLP, Libro de Acuerdos del Cabildo 1567-1570, Acta del día 22 de abril de 1569.

105 MORALES PADRÓN (1970), p. 236.

106 HERNÁNDEZ MARTÍN, L. (2000), p. 25.

107 AMSCLP, Libro de Acuerdos del Cabildo 1559-1567, Acta del día 10 de mayo de 1563

108 AMSCLP, Libro de Acuerdos del Cabildo 1567-1570, Acta del día 17 de febrero de 1568.

109 AMSCLP, Libro de Acuerdos del Cabildo 1567-1570, la fecha del acta se encuentra ilegible, pero por la fecha de las actas anteriores y posteriores, deducimos que es el acta del viernes 20 de mayo de 1568 .

110 AMSCLP, Libro de Acuerdos del Cabildo 1567-1570, dado que la fecha del acta está ilegible, deducimos que se trata de un acuerdo entre el 9 y el 23 de julio de 1568.

111 AMSCLP, Libro de Acuerdos del Cabildo 1571-1586, Acta del día 3 de septiembre de 1579. 
como el inventario de la artillería y demás cosas de las citadas fortalezas ${ }^{112}$. Tomada la posesión nombró como persona para que asista a la fortaleza del puerto a Pedro Hernández Señorino.

\section{Torre del Cabo}

Este baluarte se encontraba en la puerta de la ciudad por la parte norte, al pie de unos riscos, terminando con él la cortina de fortificaciones que se hicieron en este siglo ${ }^{113}$.

La construcción se iniciaría en el año 1568, sobre todo con el objeto de defender aquella parte de la ciudad, donde existían abrigos y pequeñas playas utilizadas por el enemigo para desembarcar. Este distaba de la fortificación de Santa Catalina unas 269 varas y se consideraba que su ubicación era perfecta para impedir que por aquella parte desembarcara el enemigo. Torriani proyectó reformar dicho baluarte en un informe que hace en 1590, calculando su costo en unos 5.000 ducados. Posteriormente el ingeniero Próspero Casola propondrá algo similar. Era de forma circular, con plaza rectangular y estrecha. De hecho, este ingeniero señalaba que dicha fuerza era fácil de fortificar y que se podía guardar también con pocos hombres, al estar ubicada en parte fuerte de manera natural ${ }^{114}$.

\section{CONCLUSIONES}

A modo de conclusión, podemos afirmar que la situación defensiva palmera se vislumbró desde el momento de la conquista hasta 1553 como ampliamente insuficiente e ineficiente. Paradójicamente, el feroz ataque de François Le Clerc (Pie de Palo) a la isla en 1553 supone un punto de inflexión en el desarrollo de las fortificaciones defensivas palmeras, que hasta este momento tan sólo contaban con la torre de San Miguel. De esta manera, mediante el refuerzo de la citada torre, más las construcciones del castillo de Santa Catalina y del fuerte del Cabo, se desarrolla un complejo defensivo capaz de repeler los ataques foráneos posteriores, como el acaecido en 1585 por parte del corsario inglés Francis Drake. En todo ello contribuye de manera determinante, tanto en este período como en la posteridad, la llegada a la isla de dos ingenieros militares que estudian pormenorizadamente los sistemas defensivos palmeros. Los trabajos de Leonardo Torriani, primero, y Próspero Casola, después, ayudan decisivamente a eliminar cualquier atisbo de debilidad en aquellas zonas de Santa Cruz de La Palma donde tradicionalmente existieron problemas para su defensa: por el norte, en el barrio del Cabo, y por el sur, por la zona de Bajamar. Desde este momento, la ciudad se halló adecuadamente protegida a los ataques de los corsarios, a pesar de que durante los siglos posteriores la ferocidad de las ofensivas no se comparó en absoluto con las sufridas por la isla durante la segunda mitad del siglo XVI.

Así, como innovaciones del presente estudio, aportamos las nuevas fuentes surgidas a raíz del análisis de las Actas del Cabildo de La Palma, así como la documentación aparecida en el Archivo de la Casa Condal, en su carpeta Próspero Casola, lo que ha desembocado en una interpretación de fuentes diferentes a las tradicionalmente establecidas entre las originales y bibliográficas para los estudios anteriores referentes a esta temática.

\section{FUENTES PRIMARIAS}

- Archivo Municipal de Santa Cruz de La Palma

○ Libro de Acuerdos del Cabildo 1559-1567.

- Libro de Acuerdos del Cabildo 1567-1570.

○ Libro de Acuerdos del Cabildo 1571-1585.

112 AMSCLP, Libro de Acuerdos del Cabildo 1571-1586, Acta del día 15 de enero de 1580.

113 PINTO DE LA ROSA (1996), pp. 379-383.

114 LOBO y BRUQUETAS (2014), p. 396. 
- Archivo Casa Condal de la Vega Grande de Guadalupe, Carpeta Próspero Casola.

- Archivo de Simancas, Sección del Consejo de Guerra, Mar y Guerra.

\section{REFERENCIAS}

AZNAR VALLEJO, E. (1983). La integración de las Islas Canarias en la Corona de Castilla (1478-1526). Aspectos administrativos, sociales y económicos. La Laguna-Sevilla: Universidad de La Laguna, Universidad de Sevilla.

CASTELLANO GIL, J. (1991). Historia de las fortificaciones de la isla de La Palma. La Laguna: Centro de la Cultura Popular Canaria.

FERNÁNDEZ, J. (2001). «Leonardo Torriani, arquitecto y urbanista en Canarias». Ciclo de Conferencias "Cátedra Cultural General Gutierrez", Actuación de los ingenieros militares en Canarias, siglos XVI al XX. núm. 5, pp. 55-72.

FRUTUOSO, G. (1964). Las Islas Canarias, de "Saudades da Terra". La Laguna: Instituto de Estudios Canarios.

HERNÁNDEZ MARTín, L. (2000). Protocolos de Domingo Pérez, escribano público de La Palma (1554-1556). Santa Cruz de La Palma: Caja General de Ahorros de Canarias.

LOBO CABRERA, M. (2018). Álvaro Alvarado y Antonio Pamo Chamoso. Los ataques de Drake y Van der Does a Las Palmas. Madrid: Mercurio.

LOBO, M. y BRUQUETAS, F. (2014). El ingeniero militar Próspero Casola y Canarias (escritos, informe y descripciones). Las Palmas de Gran Canaria: Cabildo de Gran Canaria.

LORENZO RODRÍGUEZ, J. B. (1987). Noticias para la historia de La Palma. La Laguna-Santa Cruz de La Palma: Cabildo Insular de La Palma, Tomo I.

MARCO DORTA, E. (1943). «Descripción de las Islas Canarias por virtud del mandato de Su Majestad, por un tío del Licenciado Valcárcel». Revista de Historia, número 63, pp. 197-204

MARRERO, M.; SOLANO, E. y DÍAZ, G. (2005). Acuerdos del Cabildo de La Palma, 1554-1556. Santa Cruz de La Palma: Cabildo Insular de La Palma.

MARTÍN RODRÍGUEZ, F. (1986). La primera imagen de Canarias: los dibujos de Leonardo Torriani. Tenerife: Colegio Oficial de Arquitectos de Canarias.

MARTÍN RODRÍGUEZ (1995). Santa Cruz de La Palma: la ciudad renacentista. Madrid: Cepsa.

MORALES PADRÓN, F. (1970). Cedulario de Canarias. Sevilla: Escuela de Estudios Hispanoamericanos de Sevilla, Volumen I.

NÚÑEZ, J. et ALII (1999). Catalogo de documentos del Concejo de La Palma (15011812). La Laguna: Instituto de Estudios Canarios, Tomo I.

ORTIGUEIRA, J. A.; POGGIO, M.; HERNÁNDEZ, V. y HERNÁNDEZ, L. A. (2014). «La expedición de Francis Drake a las Indias Occidentales (1585-1586) y el ataque de Santa Cruz de La Palma: apuntes de estrategia naval y otras noticias histórico-culturales». Tebeto: Anuario del Archivo Histórico Insular de Fuerteventura. ANEXO 7: Piratería en Canarias: Francis Drake, pp. 107-186.

PINTO DE LA ROSA, J. (1996). Apuntes para las antiguas fortificaciones de Canarias. Santa Cruz de Tenerife: Museo Militar Regional de Canarias.

POGGIO CAPOTE, M. (2014). «Santa Cruz de La Palma y Francis Drake». Presentación, en Tebeto: Anuario del Archivo Histórico Insular de Fuerteventura. ANEXO 7: Piratería en Canarias: Francis Drake, pp. 11-18.

POGGIO, M.; REGUEIRA, L. y HERNÁNDEZ, V. (2014). «El ataque de Francis Drake a Santa Cruz de La Palma según Pedro de Liaño (1585-1587)». Tebeto: Anuario del Archivo Histórico Insular de Fuerteventura. ANEXO 7: Piratería en Canarias: Francis Drake, pp. 187-285.

RUMEU DE ARMAS, A. (1946). «Don Juan de Monteverde, capitán general de la isla de La Palma». El Museo Canario, no 19, pp. 1-19. 
RUMEU DE ARMAS, A. (1991). Canarias y el Atlántico: Piraterías y ataques navales. Santa Cruz de Tenerife: Viceconsejería de Cultura y Deportes, Tomo I, Tomo II (primera parte).

SÁNCHEZ RODRÍGUEZ, M. (1953). «Notas históricas sobre las antiguas fortificaciones de la isla de La Palma». En YANES CARRILLO, A. (coord.): Cosas viejas de la mar. Santa Cruz de La Palma, pp. 131-134.

SANTANA PÉREZ, G. (2014). «Comercio palmero en el tránsito del siglo XVI al XVII: Tras el signo del ataque de Drake». Tebeto: Anuario del Archivo Histórico Insular de Fuerteventura. ANEXO 7: Piratería en Canarias: Francis Drake, pp. 73-89.

TORRIANI, L. (1959). Descripción de las Islas Canarias. Santa Cruz de Tenerife: Goya Ediciones.

VIERA y CLAVIJO, J. (1967). Noticias de la Historia General de las Islas Canarias. Santa Cruz de Tenerife: Goya Ediciones. 